\title{
Action-Oriented Population Nutrition Research: High Demand but Limited Supply
}

Judy Pham, ${ }^{a}$ David Pelletier ${ }^{a}$

Action-oriented research in nutrition, vital to guiding effective policies and programs at scale, is greatly underrepresented in public health journals and, even more so, in nutrition journals.

\begin{abstract}
Background: The relatively rapid ascendancy of nutrition and health on policy agendas, along with greater emphasis on accountability and results, has stimulated interest in new forms of research to guide the development and implementation of effective policies, programs, and interventions- what we refer to as action-oriented research. To date, action-oriented research in the nutrition field is thought to be the exception rather than the rule, but empirical evidence to support this claim is lacking.
\end{abstract}

Methods: We conducted a survey of selected journals in nutrition and public health to assess the extent and nature of population nutrition research published in 2012 that embodied 5 defined characteristics of action-oriented research in relation to: (1) topic(s) of study, (2) processes/influences, (3) actors, (4) methods, and (5) approaches. We identified 762 articles from the 6 selected nutrition journals and 77 nutrition-related articles from the 4 selected public health journals that met our search criteria.

Results: Only $7 \%$ of the 762 papers in nutrition journals had at least 1 of the 5 action-oriented research characteristics, compared with $36 \%$ of the 77 nutrition-related papers in the public health journals. Of all 80 articles that had at least 1 action-oriented research characteristic, only 5 articles (6.25\%) embodied all 5 characteristics. Articles with actionoriented research covered a broad range of topics and processes/influences, including policy, workforce development, and schools, as well as actors, such as program staff, store owners, parents, and school staff. In addition, various research methods were used, such as stakeholder analysis, ethnographic narrative, iterative action research, and decision tree modeling, as well as different approaches, including participant-observer and community-based participatory research.

Conclusions: Action-oriented research represents a small fraction of articles published in nutrition journals, especially compared with public health journals. This reinforces recent calls to expand population nutrition research agendas to more effectively inform and guide the initiation, development, implementation, and governance of policies, programs, and interventions to address the varied forms of nutrition-related problems. With heightened attention to the magnitude and importance of nutrition problems worldwide, there are substantial reasons and opportunities to incentivize and support such expansion.

\section{INTRODUCTION}

$\mathbf{N}$ utrition is now recognized as a major cause or contributing factor to a wide range of diseases and to the global burden of disease in developed as well as developing countries. ${ }^{1}$ In addition to its role in morbidity and mortality, poor nutrition can increase health care costs, and it contributes negatively to cognitive and motor development, school performance,

${ }^{a}$ Cornell University, Division of Nutritional Sciences, Ithaca, NY, USA. Correspondence to David Pelletier (dlp5@cornell.edu). economic productivity, and national economic growth. $^{2-6}$ For these reasons, and as a fundamental aspect of human rights and equity, nutrition has risen on the agendas of international organizations, governments in developed and developing countries, the private sector, and in popular culture. ${ }^{7-9}$ This rapid ascendancy of nutrition on policy agendas has some similarities to the ascendancy of global health that began a decade or two earlier. ${ }^{10}$ One of the key features they share in common is a greater concern for accountability and results. ${ }^{1-13}$ 
The concern for accountability and results has revealed a yawning gap in funding between mechanistic or efficacy research and research

Universal coverage of existing interventions could reduce child mortality by twothirds, but $97 \%$ of child health research grants focus on developing new interventions.

\section{New forms of research, referred to here as action- oriented research, aim to guide effective health and nutrition policies and programs.}

\section{Action-oriented research involves greater interaction with communities, government, NGOs, and the} private sector than conventional science. aimed at delivering results at scale. For instance, the Lancet child survival series estimated in 2003 that global child mortality could be reduced by two-thirds through universal coverage of existing interventions, ${ }^{14}$ but a separate analysis revealed that $97 \%$ of child health research grants are focused on developing new interventions rather than enhancing the delivery of existing interventions. ${ }^{15}$

The recognition of these gaps and the desire to produce results at scale have generated interest in newer forms of research to guide the initiation, development, implementation, and governance of effective policies and programs. Research for these purposes involves research questions, designs, methods, partnerships, and funding that are distinct from the well-developed forms of research, such as randomized controlled trials, used in discovery or efficacy research. ${ }^{16}$ The newly emergent forms of research come under a variety of labels such as implementation or delivery science, ${ }^{17}$ translational research, ${ }^{18,19}$ communitybased participatory research, ${ }^{20}$ action research, ${ }^{21}$ developmental evaluation, ${ }^{22}$ and engaged or prospective policy research, ${ }^{23}$ among others. ${ }^{24}$ Although all these types of research share a desire to create knowledge that can inform and guide solutions to health and nutrition problems, they differ markedly in the geographic scale (communities and countries to global institutions), objects of inquiry (e.g., health workers, managers, mHealth, training and supervision approaches), disciplinary theories and methods (anthropology and management to economics and political science), and the journals in which the findings are published. The advent of Global Health: Science and Practice is one manifestation of this growing interest in producing and disseminating practiceoriented knowledge and experience.

While this diversity in action-oriented health and nutrition research is a potential strength and is appropriate given the diversity in contexts where action must take place, it also poses a danger in that results from these emergent forms of research may remain highly particularistic and contextual. ${ }^{25}$ If these new forms of research are to gain legitimacy and form a coherent and cumulative body of knowledge about how to address health and nutrition problems in diverse contexts, there will need to be some parallel intellectual work to develop, refine, and share integrative knowledge, theory, frameworks, and methods. ${ }^{16}$
To this end, we recently published a framework for organizing and ultimately advancing the knowledge, principles, and practices related to action-oriented research in population nutrition, most of which deal with the implementation of policies, programs, and interventions. ${ }^{26}$ Although that paper focused on nutrition, the framework and principles are equally relevant for global health more broadly and for other domains. The present paper provides a brief overview of the framework and reports on the results of a literature search designed to assess the extent to which and how researchers are currently working at these research frontiers in the case of nutrition.

\section{A FRAMEWORK FOR DEFINING ACTION- ORIENTED NUTRITION RESEARCH}

Implementation research and the other newly emergent forms of research in health and nutrition noted above are actually part of a larger transformation in science that is underway at the societal level. In the sociology of science literature, this transformation has been famously termed "Mode 2" knowledge production. 27,28 According to this literature, the conventional production of scientific knowledge ("Mode 1") takes place primarily in academic and scientific institutions and is governed by the norms of scientific disciplines, whereas Mode 2 knowledge production takes place through greater interaction with communities, government actors, NGOs, and/or private-sectors actors. Mode 2 knowledge production is considered an emergent and socially robust form that complements Mode 1 and is especially needed for addressing complex social problems. Its emergence is due to external (societal) trends and pressures, such as the demand for greater accountability, as well as internal forces and incentives within universities and other research institutions.

According to these authors, Mode 2 knowledge production differs from that of Mode 1 in several ways:

- It takes place in the context of application or problem solving (versus theoretical or strictly academic contexts).

- It is transdisciplinary (versus disciplinary or even interdisciplinary), drawing upon whichever disciplinary and contextual knowledge is needed to address the problem at hand.

- It is heterogeneous in its sites, including mission-focused research centers, government 
agencies, think tanks, nonprofit agencies, communities of practice, epistemic communities, and community organizations (versus universities and research centers).

- It arises from mutual interaction among these actors and sites (versus interaction mainly among academic peers).

- It involves novel forms of quality control based on economic, political, social, ethical, and utility criteria (versus discipline-based norms and peer review alone).

- As a result of the social interaction, it is reflexive (embracing of multiple perspectives on problem solving versus search for a single truth) and more intentionally socially accountable (versus accountable only to scientific and disciplinary norms).

Based on this earlier work, we proposed 6 dimensions or tendencies that might define action-oriented population nutrition research (Table 1). ${ }^{26}$ These dimensions resonate well with the current understanding of implementation research as elaborated elsewhere, ${ }^{24,29}$ but the present study did not limit itself to that focus.

The 6 dimensions are:

1. Why we study ("why"): the central feature of action-oriented research, influencing all other dimensions. The primary motivation of action-oriented research is to help identify, characterize, and solve practical problems.

2. What we study ("topics"): examine food and nutrition issues in a broader context beyond individual-level biology and behavior, including a focus on food systems, social and public health programs and policies, organizational behavior, and change processes at various levels of social organization

3. Who we study ("actors"): also moves beyond the individuals directly affected (mothers, infants, consumers, etc.) and instead studies those engaged in food and nutrition efforts directly or indirectly, such as government agencies, policy makers, frontline workers, civil society organizations, academic institutions, and private-sector actors

4. How we study in terms of methods ("methods"): a range of qualitative and quantitative methods that may include but go beyond the conventional methods of focus groups, interviews, and/or surveys that measure knowledge, attitudes, beliefs, behavior, and biology
5. How we study in terms of approaches ("approaches"): involves interaction between researchers and various social actors, and thus can be described as engaged and participatory as opposed to detached and seeking objectivity

6. Disciplinary foundations ("disciplines"): draws upon the conventional disciplines (e.g., nutritional sciences, epidemiology, and behavioral psychology) but also includes perspectives, theories, and collaboration from other disciplines, such as anthropology, economics, law, policy analysis, and management. Importantly, the motivation of creating actionable knowledge often leads to a transdisciplinary orientation, in which the disciplines, theories, and constructs used in a particular case are defined based on the characteristics of the problem in a given context, rather than the disciplinary norms of the researchers and/or their institutions.

According to Pelletier et al., ${ }^{26}$ action-oriented research currently is the exception rather than the rule in population nutrition research, and there is a need to expand in these directions in order to develop more effective, appropriate, and sustainable responses to food and nutrition problems. The purpose of this paper is to provide systematic empirical support for that claim.

\section{METHODS}

Based on the 6-dimension framework, we developed and applied a literature coding system to peer-reviewed literature published in 2012 from selected journals in the areas of nutrition and public health. The public health journals were included to provide a contrast with the nutrition journals. We modeled our coding system after a methodology applied to examine the use of social-ecological approaches in the design of health promotion interventions over a 20 -year period. ${ }^{30}$ We also consulted the Preferred Reporting Items for Systematic Reviews and MetaAnalyses (PRISMA) statement for guidance. ${ }^{31}$

Purposeful sampling was used to focus on the journals most likely to publish action-oriented research, through consultation with nutrition colleagues familiar with the field.

The nutrition journals selected were:

- Ecology of Food and Nutrition

- Journal of Nutrition Education and Behavior

- Maternal and Child Nutrition

- Journal of Nutrition 
TABLE 1. Six Dimensions of Action-Oriented Population Nutrition Research ${ }^{a}$

\begin{tabular}{ll}
\hline Dimension & Conventional Research \\
\hline Why we study & $\begin{array}{l}\text { To create generalizable or fundamental knowled } \\
\text { that answers scientific questions }\end{array}$ \\
$\begin{array}{ll}\text { What we } \\
\text { study (topics) }\end{array}$ & $\begin{array}{l}\text { Nutrients, food and nutrient intake, consumer } \\
\text { behavior, determinants and consequences of } \\
\text { nutritional variation, efficacy of interventions }\end{array}$
\end{tabular}

Who we study Mothers, infants, children, individuals, consumers, (actors) patients

\section{How we study:} methods

\section{How we study: approaches}

\section{Disciplinary foundations}

Measurements of knowledge, attitudes, beliefs, behavior, biology, individual and environmental characteristics, and their interrelationships, using a limited range of quantitative and qualitative methods

Generally detached, objectivist, positivist, reductionist, behaviorist, hypothesis testing

Nutritional sciences, epidemiology and biostatistics, biomedicine, psychology, social psychology, consumer behavior

\section{Action-Oriented Research}

To create knowledge that can help identify, characterize, and solve practical problems of concern to stakeholders, organizations, communities, or publics at various scales

Food and nutrition issues, causes, and solutions in a broader social and action context, including food systems, social and public health programs and policies; processes of policy agenda setting, governance, development, implementation, scalingup, and evaluation; and community and organizational behavior and change processes

Policy makers, analysts, managers, implementers, frontline workers in the public sector; global, national, state, and local leaders and members of communities civil society organizations, universities, networks, and coalitions; global, national, state, and local privatesector actors and entities, citizens, academics

More eclectic range of qualitative and quantitative methods to inquire into the new topics noted above, including mixed methods, social network analysis, discourse analysis, narrative policy analysis, $Q$ methodology, process tracing, stakeholder analysis and influence mapping, program impact pathways, organizational ethnography, systems dynamics group modeling

More engaged, participatory, action research, community-based participatory research, participant-observer, reflection in action, embedded, critical, social construction, emergent, systemsand complexity-oriented

Transdisciplinary, drawing upon our traditional disciplines but also with a greater role for economics, sociology, anthropology, policy analysis, law, urban planning, political science, organizational behavior, management sciences, and systems sciences

a In many cases, the distinctions shown in this table are a matter of degree or emphasis rather than discrete categories. Individual studies or research programs may possess many or few of these characteristics, to a greater or lesser extent.

Reprinted and adapted with permission from Pelletier et al., 2013 in Advances in Nutrition. ${ }^{26}$ Copyright 2013 by American Society for Nutrition.

- Public Health Nutrition

- International Journal of Behavioral Nutrition and Physical Activity

The public health journals selected were:

- American Journal of Public Health

- Health Policy and Planning

- Social Science e Medicine

- Journal of School Health
We used the Thomas Reuters Web of Science database to screen all articles published in 2012 in these journals. After eliminating papers not focused at the population level and/or not focusing on nutrition (described below), the remaining articles were sorted by using a coding sheet initially based on the 6 action-oriented research dimensions. The coding was refined using successive trial runs, and the final coding sheet included 5 dimensions that could be 
systematically and objectively identified in the articles.

The final 5 characteristics, which required some modifications to the original 6 dimensions to embrace the actual diversity found in the articles, comprised: (1) topic(s) of study, (2) processes/influences, (3) actors, (4) methods, and (5) approach. Characteristics 3, 4, and 5 are from the original framework. We eliminated the "why" and "disciplines" dimensions from the original framework due to limitations in our ability to identify them without making assumptions about authors' intentions or the nature or extent of any transdisciplinary orientation. Characteristics 1 and 2 in our study corresponded to the "topics" dimension from the original framework but was divided into 2 categories to distinguish papers that focused on entities (e.g., interventions and public programs) from papers that focused on processes or influences (e.g., policy development, community or organizational change).

For the nutrition journals, we first eliminated papers that focused narrowly on topics such as measurement of body mass index, birth weight (without any nutritional correlates), pregnancy cravings, tobacco, physical activity, disease, aging, oral health, or housing, based on article titles and abstracts when necessary. In the second stage, the remaining papers were hand-sorted with the coding sheet by title, abstract, and full text, as necessary. Those embodying none of the actionoriented characteristics were also eliminated. One reviewer (JP) tabulated the titles and abstracts for the final papers included in our analysis according to each characteristic and noted the reason(s) for the tabulation, while another reviewer (DP) reviewed all tabulations. In cases where there was disagreement, the reviewers met to discuss until they reached agreement.

For the public health journals, we identified nutrition-related papers by using the following search terms in the topic search field, using the Web of Science database: nutrition OR malnutrition $O R$ undernutrition $O R$ food $O R$ obesity $O R$ micronutrient $O R$ supplementation $O R$ nutrient $O R$ diet $O R$ hunger. Those papers not meeting any of these search criteria were considered non-nutrition articles and were not considered further. The articles meeting the nutrition search criteria were subjected to the same coding and review protocol as the nutrition journal papers, to identify the subset with at least 1 action-oriented research characteristic.

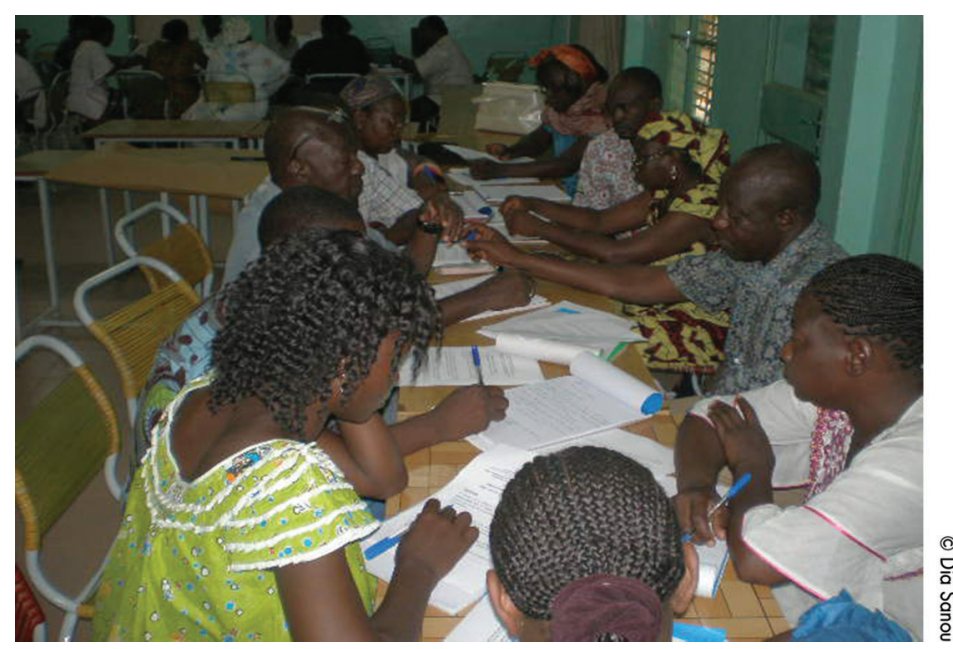

Participants in Mali analyze data on infant and young child feeding practices during a community diagnosis. Such participatory and actionoriented research methods tend to examine health problems in a broader context and involve community actors in the research process itself.

\section{RESULTS}

After employing our first-stage elimination strategies in which we excluded articles in nutrition journals with a narrow topic and articles in public health journals that did not meet our nutrition search terms criteria, we identified and reviewed a total of 839 articles (762 from nutrition journals, 77 from public health journals). Overall, less than $10 \%$ of these articles possessed at least $\mathrm{l}$ action-oriented research characteristic and were ultimately included in our analysis $(n=52$ from nutrition journals, $\mathrm{n}=28$ from public health journals) (Table 2). (See the supplementary material for a bibliography of the papers with at least $\mathrm{l}$ action-oriented research characteristic, which were included in our analysis.)

Of the 80 articles that had at least 1 actionoriented research characteristic, 5 articles (6.25\%) embodied all 5 characteristics. There was a notable difference in the frequency of actionoriented research articles between the nutrition journals ( $7 \%$ with at least 1 characteristic) and the public health journals (36\%).

\section{Action-Oriented Research in Nutrition Journals}

Of the 52 articles from nutrition journals that had 1 or more action-oriented research characteristic, $69 \%$ fulfilled the criteria for "topic(s) of study," $81 \%$ for "processes/influences," $44 \%$ for "actors," $31 \%$ for "method," and $31 \%$ for "approach"

\section{Nutrition articles were coded based on 5 action- oriented research characteristics: topic, processes/ influences, actors, methods, and approach.}

Less than $10 \%$ of nutrition articles published in 2012 embodied at least 1 action-oriented research characteristic.

\footnotetext{
Public health journals had a higher proportion of action-oriented nutrition research articles than nutrition journals.
} 
TABLE 2. Nutrition-Focused Papers With Action-Oriented Research Characteristics Published in 2012 in Nutrition and Public Health Journals

\begin{tabular}{|c|c|c|c|c|c|c|c|}
\hline \multirow[b]{2}{*}{ Journal Name } & \multirow{2}{*}{$\begin{array}{l}\text { Total No. of } \\
\text { Nutrition Papers } \\
\text { in } 2012\end{array}$} & \multirow{2}{*}{$\begin{array}{l}\text { No. }(\%) \text { of Papers } \\
\text { With } \geq 1 \\
\text { Action-Oriented } \\
\text { Characteristic }^{\mathbf{a}}\end{array}$} & \multicolumn{5}{|c|}{ No. (\%) of Papers per Action-Oriented Characteristic ${ }^{b}$} \\
\hline & & & $\begin{array}{l}\text { Topic(s) of } \\
\text { study }\end{array}$ & $\begin{array}{l}\text { Processes/ } \\
\text { Influences }\end{array}$ & Actors & Methods & Approach \\
\hline \multicolumn{8}{|l|}{ Nutrition Journals } \\
\hline $\begin{array}{l}\text { Ecology of Food and } \\
\text { Nutrition }\end{array}$ & 19 & $4(21.1)$ & $3(75.0)$ & $4(100.0)$ & $1(25.0)$ & $2(50.0)$ & $2(50.0)$ \\
\hline $\begin{array}{l}\text { Journal of Nutrition } \\
\text { Education and } \\
\text { Behavior }\end{array}$ & 90 & $13(14.4)$ & $6(46.2)$ & $11(84.6)$ & $6(46.2)$ & $3(23.1)$ & $4(30.8)$ \\
\hline $\begin{array}{l}\text { Maternal and Child } \\
\text { Nutrition }\end{array}$ & 47 & $5(10.6)$ & $5(100.0)$ & $4(80.0)$ & $5(100.0)$ & $2(40.0)$ & $3(60.0)$ \\
\hline Journal of Nutrition & 308 & $7(2.3)$ & $6(85.7)$ & $5(71.4)$ & $1(14.3)$ & $0(0.0)$ & $0(0.0)$ \\
\hline Public Health Nutrition & 252 & $22(8.7)$ & $15(68.2)$ & $17(77.3)$ & $9(40.9)$ & $9(40.9)$ & $7(31.8)$ \\
\hline $\begin{array}{l}\text { International Journal of } \\
\text { Behavioral Nutrition } \\
\text { and Physical Activity }\end{array}$ & 46 & $1(2.2)$ & $1(100.0)$ & $1(100.0)$ & $1(100.0)$ & $0(0.0)$ & $0(0.0)$ \\
\hline Subtotal & 762 & $52(6.8)$ & $36(69.2)$ & $42(80.8)$ & $23(44.2)$ & $16(30.8)$ & $16(30.8)$ \\
\hline \multicolumn{8}{|l|}{ Public Health Journals } \\
\hline $\begin{array}{l}\text { American Journal of } \\
\text { Public Health }\end{array}$ & 24 & $8(33.3)$ & $8(100.0)$ & $7(87.5)$ & $3(37.5)$ & $4(50.0)$ & $0(0.0)$ \\
\hline $\begin{array}{l}\text { Health Policy and } \\
\text { Planning }\end{array}$ & 4 & $4(100.0)$ & $4(100.0)$ & $4(100.0)$ & $2(50.0)$ & $4(100.0)$ & $3(75.0)$ \\
\hline $\begin{array}{l}\text { Social Science \& } \\
\text { Medicine }\end{array}$ & 26 & $7(26.9)$ & $7(100.0)$ & $5(71.4)$ & $3(42.9)$ & $4(57.1)$ & $3(42.9)$ \\
\hline $\begin{array}{l}\text { Journal of School } \\
\text { Health }\end{array}$ & 23 & $9(39.1)$ & $9(100.0)$ & $9(100.0)$ & $4(44.4)$ & $4(44.4)$ & $2(22.2)$ \\
\hline Subtotal & 77 & $28(36.4)$ & $28(100.0)$ & $25(89.3)$ & $12(42.9)$ & $16(57.1)$ & $8(28.9)$ \\
\hline TOTAL & 839 & $80(9.5)$ & $64(80.0)$ & 67 (83.8) & $35(43.8)$ & $32(40.0)$ & $24(30.0)$ \\
\hline
\end{tabular}

(Table 2). Only $2 \%$ of the articles embodied all 5 characteristics while $17 \%$ embodied only 1 characteristic, $35 \%$ embodied 2 characteristics, $25 \%$ embodied 3 characteristics, and $21 \%$ embodied 4 characteristics (Figure).

The "topic(s) of study" and "processes/ influences" covered a broad range of topics, including national policy, workforce development, programs, and schools, among others (Table 3 ). One illustrative example in workforce development was an article titled, "Using video narratives of women's lived experience of breastfeeding in midwifery education: exploring its impact on midwives' attitudes to breastfeeding," which studied midwifery breastfeeding counseling as the topic of study and the midwives' attitudes toward breastfeeding as the outcome. ${ }^{32}$ Another article, "Public health nutrition workforce development in seven European countries: constraining and enabling factors," studied public health nutrition workforce development in 7 European countries as the topic of study and constraining and enabling 
FIGURE. Number of Action-Oriented Research Characteristics in Nutrition Papers by Journal Type $(\mathrm{N}=80)$

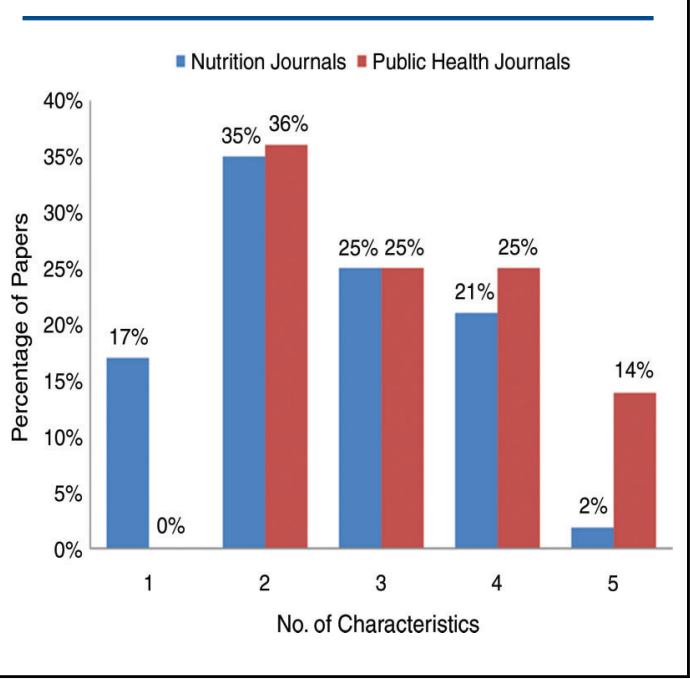

factors in terms of the policy environment, public health organizations, and workforce compensation as the processes/influences. ${ }^{33}$

The "actor" characteristic in the actionoriented research articles included program staff, private-sector stakeholders, store owners, government employees, parents, school staff, and peer supporters, among others (Table 4). Various research "methods" were used, including stakeholder analysis, onsite receipt collection, ethnographic narrative, and iterative action research (Table 4), and "approaches" consisted of participant-observer, engaged, complexity-aware and prospective policy research, and communitybased participatory research (not shown).

\section{Action-Oriented Research in Public Health Journals}

Of the 28 articles in public health journals with 1 or more action-oriented research characteristic, $100 \%$ fulfilled the criterion for "topic(s) of study,"

TABLE 3. Illustrations of Action-Oriented Research Characteristics of "Topic(s) of Study" and "Processes/Influences" in Nutrition Journals

\begin{tabular}{ll}
\hline Key Topics & Topic(s) of Study \\
\hline $\begin{array}{l}\text { National } \\
\text { policy }\end{array}$ & $\begin{array}{l}\text { US, Ireland, UK, dietary guidelines, growth charts, } \\
\text { nutrition in child-care settings, revision process, } \\
\text { development process, communications initiatives }\end{array}$ \\
$\begin{array}{l}\text { Workforce } \\
\text { development }\end{array}$ & $\begin{array}{l}\text { Certification programs, register of nutritionists, required } \\
\text { core functions, teaching and training initiatives, } \\
\text { midwifery breastfeeding counseling }\end{array}$ \\
Programs & $\begin{array}{l}\text { Public-private partnerships, church-based, } \\
\text { transdisciplinary platforms for interventions, e.g., health, } \\
\text { agriculture, market, social protection }\end{array}$
\end{tabular}

Schools Nutrition guidelines, school gardens

Global Immigrant experience, political instability, economic instability, drought, global food system, regional early warning systems

Other Media content, employers' attitudes toward motherfriendly work environments, breastfeeding peer support services, grocery store marketing and promotion, WICauthorized stores

\section{Processes/Influences}

Translation at local/regional levels, barriers to and extent of adoption, revisions, evaluation, practitioners' understanding of growth charts, cost implications, public health expenditures

Constraining/enabling factors, stakeholder consensus on core functions, incorporating cognitive-behavioral techniques into breastfeeding counseling

Partnership opportunities, changed program practices, cost-effectiveness, challenges for dissemination, new evaluation framework, development of young adult obesity program based on community-based participatory research, implementation fidelity

Instructional process, decision making, environment, food service offerings, food preparation practices

Food nostalgia and cultural symbolism, household provision of care for people living with HIV/AIDS, real cost of food, policy options to improve food security, ability to predict food crises

Confusion resulting from media news reporting, eating maps, food store stocking and pricing behavior changes after food assistance program changes, employer readiness to provide breasffeeding accommodations, marketing on packaging

Abbreviation: WIC, Special Supplemental Nutrition Program for Women, Infants, and Children. 


\begin{tabular}{ll}
\hline TABLE 4. Illustrations of Action-Oriented Characteristics of "Actors" and "Methods" in Nutrition \\
Journals \\
\hline Actors & Methods \\
\hline Child care professionals & Consultative workshops \\
Clinical staff & Emerging policy options with stakeholder input \\
Community health workers & Health economic analysis \\
Community leaders & Impact pathways \\
Food assistance program staff & Implementation pathways \\
Food service employees & Immersion-observation \\
Government authorities and advisors & Iterative action research via workshops \\
Health professionals & Onsite receipt collection \\
Peer supporters & Policy review \\
Private-sector employers & Simulation of food intake patterns \\
Program implementers & Stakeholder analysis \\
School staff, parents, volunteers & Systematic Internet review \\
Stakeholders, i.e. academics, practitioners & Thematic analysis
\end{tabular}

Store owners/managers

$89 \%$ for "processes/influences," $43 \%$ for "actor," $57 \%$ for "method," and 29\% for "approach" (Table 2). None of these papers embodied only 1 action-oriented research characteristic, $36 \%$ embodied 2 characteristics, 25\% embodied 3 characteristics, $25 \%$ embodied 4 characteristics, and $14 \%$ embodied all 5 characteristics (Figure).

In the public health journals, the "topic(s) of study" and "processes/influences" covered a broad range of topics, as in the nutrition journals, including policy and legislation, schools, and programs (Table 5). The "actor" category included midwives, school principals, community members, and NGOs, among others (Table 6). Some examples of the "methods" included change-making process analysis, exploratory case study, consultative workshops, and decision tree modeling, and the "approaches" comprised participant-observer, community-based participatory research, engaged, and prospective policy research (not shown).

\section{DISCUSSION}

This paper argues that much health policy [research] wrongly focuses attention on the content of reform, and neglects the actors involved in policy reform (at the international, national and subnational levels), the processes contingent on developing and implementing change and the context within which policy is developed. Focus on policy content diverts attention from understanding the processes which explain why desired policy outcomes fail to emerge. ${ }^{34}$

The above quote from 20 years ago refers to the state of research on health policy in developing countries, but it could just as well apply to much of population nutrition research today. The present study, consistent with the claims made by Pelletier et al. in the earlier paper that outlined a framework for defining action-oriented nutrition research, ${ }^{26}$ finds a paucity of research on the actors, processes, and contexts within which nutrition policy (or actions in general) is developed and implemented, suggesting that the majority of nutrition research currently being published by nutrition and public health academics contains a relatively narrow range of topics, methods, and approaches. Specifically, fewer than $10 \%$ of the reviewed nutrition articles embodied at least 1 action-oriented research 
TABLE 5. Illustration of Action-Oriented Research Characteristics of "Topic(s)" and "Processes/Influences" in Public Health Journals

\begin{tabular}{ll}
$\begin{array}{l}\text { Key } \\
\text { Topics }\end{array}$ & Topic(s) of Study \\
\hline $\begin{array}{l}\text { Policy } \\
\text { and }\end{array}$ & $\begin{array}{l}\text { Changes in WIC policy, state childhood obesity policies, } \\
\text { national nutrition agenda setting, policy formulation and } \\
\text { legislation }\end{array}$ \\
implementation
\end{tabular}

Schools Elementary/high schools, school beverage shipments, school bus advertising, school-based obesity policy, wellness policy requirements, state department of education policy and structural changes to improve nutrition

Programs Outcomes and cost of community-based management of acute malnutrition, procedural programs to create healthy environments for vulnerable populations, promotional tool for healthy body image

Other Food advertising, language of midwives, GDP/Gini Index/GII, climate change, international human rights obligations regarding rights to food and health

\section{Processes/Influences}

Predictors of enactment, instruments prescribed to influence school food environment, strategies used to move nutrition agenda forward, enabling/inhibiting factors, levels of commitment, policy diffusion from state- to districtlevel

Beverage industry self-regulation, sugar-sweetened beverage availability, acceptability of specific intervention strategies, changes in wellness policies before and after federal mandates, changes in food options, food service finances, implementation and awareness of guidelines

Implementation processes, lessons learned, cost-

effectiveness, extent of cooperation, population reach, perceived potential of tool

National approaches to addressing food insecurity, impacts on gender inequality, global distribution of obesity, impacts on household decision making

Abbreviations: GDP, Gross Domestic Product; GIl, Global Innovation Index; WIC, Special Supplemental Nutrition Program for Women, Infants, and Children.

TABLE 6. Illustrations of Action-Oriented Characteristics of "Actors" and "Methods" in Public Health Journals

\section{Actors}

Community members

Frontline staff

Government officials

Midwives

NGOs, donors, civil society

Physical education teachers

Private sector

Program administrative staff

School health advisory councils

School principals

\section{Methods}

Change-making process analysis

Coding of media photos

Consultative workshops

Decision tree modeling

Discourse analysis

Document analysis

Exploratory case study

Information gathering from practitioners

Observation

Project performance framework

Systematic review

Theoretical policy science typology

Wellness policy coding scheme 


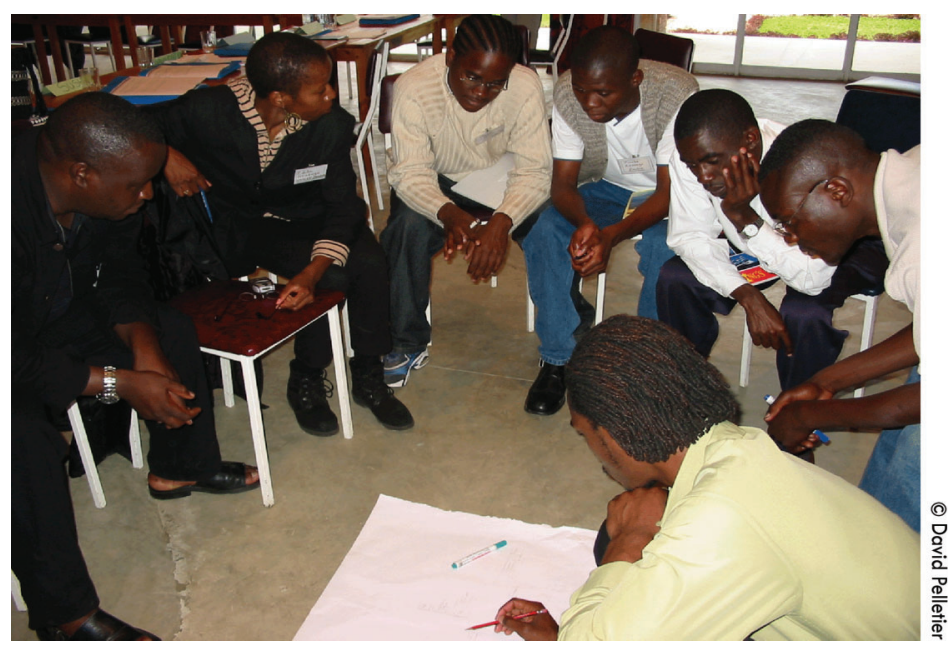

In Ghana, a group of young men map factors and locations in their community that place youth at risk for HIV. This type of youth action research trains young people in the research process, including using their findings to inform direct change in their communities.

The small set of nutrition research articles that were action-oriented exhibited a rich variety of topics, methods, and approaches, indicating such research is feasible.

\section{Effective solutions to nutrition problems require application of knowledge from both action- oriented and conventional nutrition research.}

characteristic, which itself is a minimalist criterion. Those that did meet this criterion, however, exhibited a rich array of action-oriented research topics, processes/influences, methods, and approaches to study, indicating that this type of research is feasible and can be expanded in the future.

The sizeable difference between the proportion of action-oriented research papers published in nutrition journals (only 7\% of reviewed papers had at least 1 action-oriented research characteristic) versus public health journals (36\%) suggests that articles in public health journals are more likely to be engaged in problem-solving research and to have expanded their research questions, approaches, and methods, compared with those published in nutrition science journals. It is unclear from the present study whether this difference reflects greater receptivity to action-oriented research papers in public health journals or a preference for action-oriented researchers to publish in those journals. Given the importance of action-oriented research for informing and guiding solutions to high-burden and highly salient food and nutrition problems, the present study suggests there is an undersupply of such research, especially in nutrition journals.

In fact, for at least the last 2 decades, the need for more action-oriented research has been recognized ${ }^{35-37}$ to answer such problems as how to deliver solutions effectively and sustainably at large scale, ${ }^{38}$ how to increase demand for and use of existing nutrition services and products, ${ }^{39}$ and how to ensure relevance of nutrition research to policy makers and program implementers. ${ }^{40}$ Most recently, the New York Academy of Sciences, in collaboration with the World Health Organization, launched a solution-oriented global research agenda for nutrition, ${ }^{37}$ and a new society for implementation research on nutrition is being formed for that purpose. ${ }^{41}$

The literature offers several explanations for this undersupply of action-oriented nutrition research. Allen and Gillespie discuss nutrition researchers' scientific predisposition to address questions of efficacy rather than effectiveness ${ }^{42}$; Garrett points toward nutrition researchers' limited familiarity with other disciplines and the contributions they can make ${ }^{40}$; Shekar cites the real and/or perceived lack of funding for such research ${ }^{38}$; Berg examines the academic culture and training that inhibit interest in applied research ${ }^{43}$; and nutrition stakeholders within sub-Saharan Africa identify a need for better governance of nutrition research, alignment of nutrition research funding with priorities identified within the region, and capacity development for nutrition research. The literature and experience of health policy research concurs with these explanations and also identifies a heavy reliance on international funding for research, an excessive focus on the direct utility of findings from specific studies, and a tendency to undervalue contributions from social sciences. ${ }^{44}$

The interpretation of the findings in this paper requires 2 important qualifications. First, as detailed in the original paper outlining the action-oriented research framework, ${ }^{26}$ the focus on action-oriented research is not to dismiss or discount the importance of conventional nutrition research. Rather, as noted elsewhere, $^{24}$ the design, implementation, and sustainability of effective solutions to nutrition problems require the integration of knowledge from both forms of research, so that knowledge of intervention efficacy can be combined with knowledge of and strategies for agenda setting, commitment building, policy and program formulation and implementation, and related activities.

Second, the sparseness of action-oriented research in nutrition journals raises the question: Does it matter? Perhaps what really matters is that nutrition researchers and/or researchers from 
other disciplines are doing action-oriented research and publishing it in whichever journals are receptive to such research. This may be a practical strategy in the short-term, if the current perspectives and priorities in nutrition science journals are not receptive. However, this shortterm strategy would raise concerns if it inhibits the continued intellectual growth and policy/ programmatic relevance of the nutrition research community itself or reflects an institutionalized resistance to such growth. In the long-run, it will be important for action-oriented research to become more mainstreamed within nutrition curricula, research agendas, and donor funding. The focus and content of nutrition journals play important gatekeeper, incentivizing, and symbolic functions in that mainstreaming process.

\section{Limitations}

The present study has several technical limitations. First, it focused only on a sample of nutrition and public health journals and only on papers published in 2012, in order to provide an initial sense of the current research tendencies. A more comprehensive bibliometric survey would be useful to ensure broader coverage and provide a baseline for examining trends over time. Second, the low frequency of actionoriented nutrition research articles may reflect editorial preferences of the journals rather than the actual volume of such research. The possibility of publication bias cannot be examined with these data sources alone. Third, the data for this research are based on analysis of material provided in the papers themselves, rather than on direct communication with authors, which could have resulted in some inaccurate coding. While acknowledging these issues, it also seems likely that the overall findings are rather robust to such limitations. Finally, while most of the action-oriented research papers identified through the bibliometric search in this paper are focused on topics, processes, and/or actors related to implementation of policies, programs, or interventions, it is important to note that search terms such as "implementation" or "delivery" were not employed in this study. Given the significant and growing interest in implementation research per se, a high priority for future research is to conduct a more comprehensive survey of the literature to establish benchmarks and directions for this growing field of inquiry.

\section{CONCLUSION}

Action-oriented research represents a relatively small fraction of papers published in nutrition journals, even when the search is restricted to the journals most likely to publish such research and when a minimal set of criteria is applied. Public health journals, in contrast, are far more likely to publish nutrition research with action-oriented characteristics. Existing action-oriented research exhibits a rich array of topics, methods, and approaches, indicating that this type of research is feasible and can be expanded in the future. With heightened attention to the magnitude and importance of nutrition problems worldwide and the emphasis placed on accountability and results, there are substantial opportunities and obligations for all of parties in the research enterprise, from research institutions and graduate training programs to journals and research funders, to incentivize and support such an expansion. ${ }^{45}$

Acknowledgments: The authors thank Dr. Christine Olson for her assistance in reviewing a draft of this paper.

Competing Interests: None declared.

\section{REFERENCES}

1. Lim SS, Vos T, Flaxman AD, Danaei G, Shibuya K, Adair-Rohani $\mathrm{H}$, et al. A comparative risk assessment of burden of disease and injury attributable to 67 risk factors and risk factor clusters in 21 regions, 1990-2010: a systematic analysis for the Global Burden of Disease Study 2010. Lancet. 2012;380(9859):2224-2260. CrossRef. Medline

2. Black RE, Victora CG, Walker SP, Bhutta ZA, Christian P, de Onis $M$, et al. Maternal and child undernutrition and overweight in low-income and middle-income countries. Lancet. 2013;382 (9890):427-451. CrossRef. Medline

3. World Bank. Repositioning nutrition as central to development: a strategy for large scale action. Washington (DC): The Bank; 2006. Available from: http://siteresources.worldbank.org/NUTRITION/ Resources/281846-1131636806329/NutritionStrategy.pdf

4. Chan M. Investing in early child development: an imperative for sustainable development. Ann N Y Acad Sci. 2014;1308(1): vii-viii. CrossRef. Medline

5. Black MM, Dewey KG. Promoting equity through integrated early child development and nutrition interventions. Ann N Y Acad Sci. 2014;1308(1):1-10. CrossRef. Medline

6. Cawley J, Meyerhoefer C. The medical care costs of obesity: an instrumental variables approach. J Health Econ. 2012;31 (1):219-230. CrossRef. Medline

7. Scaling Up Nutrition SUN [Internet]. New York: SUN; c2013 [cited 2013 Oct 3]. Available from: http://scalingupnutrition.org/

8. 1,000 Days Partnership [Internet]. Washington (DC): The Partnership; c2015 [cited 2013 Sep 23]. Available from: http:// www.thousanddays.org/

9. World Health Organization (WHO). 2008-2013 action plan for the global strategy for the prevention and control of 
noncommunicable diseases. Geneva: WHO; 2008. Available from: http://www.who.int/nmh/publications/ ncd_action_plan_en.pdf

10. Institute for Health Metrics and Evaluation. Financing global health 2012: the end of the golden age? Seattle (WA): The Institute; 2012. Available from: http://www.healthdata.org/ policy-report/financing-global-health-2012-end-golden-age

11. Das P. Jim Kim: new President of the World Bank. Lancet. 2012;380(9836):19. CrossRef. Medline

12. World Health Organization (WHO). Keeping promises, measuring results: Commission on Information and Accountability for Women's and Children's Health. Geneva: WHO; 2011. Available from: www.who.int/topics/ millennium_development_goals/accountability_commission/ Commission_Report_advance_copy.pdf

13. Chan M, Kazatchkine M, Lob-Levyt J, Obaid T, Schweizer J, Sidibe $M$, et al. Meeting the demand for results and accountability: a call for action on health data from eight global health agencies. PLoS Med. 2010;7(1):e1000223. CrossRef. Medline

14. Jones G, Steketee RW, Black RE, Bhutta ZA, Morris SS; Bellagio Child Survival Study Group. How many child deaths can we prevent this year? Lancet. 2003;362(9377):65-71. CrossRef. Medline

15. Leroy JL, Habicht JP, Pelto G, Bertozzi SM. Current priorities in health research funding and lack of impact on the number of child deaths per year. Am J Public Health. 2007;97(2):219-223. CrossRef. Medline

16. Shelton JD. Evidence-based public health: not only whether it works, but how it can be made to work practicably at scale. Glob Health Sci Pract. 2014;2(3):253-258. CrossRef. Medline

17. Madon T, Hofman KJ, Kupfer L, Glass RI. Implementation science. Science. 2007;318(5857):1728-1729. CrossRef. Medline

18. Glasgow RE, Emmons KM. How can we increase translation of research into practice? Types of evidence needed. Annu Rev Public Health. 2007;28(1):413-433. CrossRef. Medline

19. Butler D. Translational research: crossing the valley of death. Nature. 2008;453(7197):840-842. CrossRef. Medline

20. Minkler M, Blackwell AG, Thompson M, Tamir H. Community-based participatory research: implications for public health funding. Am J Public Health. 2003;93(8):1210-1213. CrossRef. Medline

21. Schensul JJ. Engaged universities, community based research organizations and third sector science in a global system. Hum Organ. 2010;69(4):307-320.

22. Patton M. Developmental evaluation: applying complexity concepts to enhance innovation and use. New York: Guilford Press; 2011.

23. Walt G, Shiffman J, Schneider H, Murray SF, Brugha R, Gilson L. 'Doing' health policy analysis: methodological and conceptual reflections and challenges. Health Policy Plan. 2008;23(5): 308-317. CrossRef. Medline

24. Peters DH, Adam T, Alonge O, Agyepong IA, Tran N. Implementation research: what it is and how to do it. BMJ. 2013;347:f6753 CrossRef. Medline

25. Gilson L, Raphaely N. The terrain of health policy analysis in low and middle income countries: a review of published literature 19942007. Health Policy Plan. 2008;23(5):294-307. CrossRef. Medline

26. Pelletier DL, Porter CM, Aarons GA, Wuehler SE, Neufeld LM. Expanding the frontiers of population nutrition research: new questions, new methods, and new approaches. Adv Nutr. 2013; 4(1):92-114. CrossRef. Medline
27. Nowotny H, Scott P, Gibbons M. Re-thinking science: knowledge and the public in an age of uncertainty. Cambridge (England): Polity; 2001.

28. Gibbons $M$. The new production of knowledge: the dynamics of science and research in contemporary societies. London: SAGE Publications; 1994.

29. Peters $D$, Tran N, Adam T. Implementation research in health: a practical guide. Geneva: World Health Organization, Alliance for Health Policy and Systems Research; 2013. Available from: http://apps.who.int/iris/bitstream/10665/91758/1/ 9789241506212_eng.pdf?ua $=1$

30. Golden SD, Earp JA. Social ecological approaches to individuals and their contexts: twenty years of health education \& behavior health promotion interventions. Health Educ Behav. 2012;39 (3):364-372. CrossRef. Medline

31. Knobloch K, Yoon U, Vogt PM. Preferred reporting items for systematic reviews and meta-analyses (PRISMA) statement and publication bias. J Craniomaxillofac Surg. 2011;39(2):91-92. CrossRef. Medline

32. Taylor $A M$, Hutchings $M$. Using video narratives of women's lived experience of breastfeeding in midwifery education: exploring its impact on midwives' attitudes to breastfeeding. Matern Child Nutr. 2012;8(1):88-102. CrossRef. Medline

33. Kugelberg $S$, Jonsdottir $S$, Faxelid $E$, Jönsson $K$, Fox $A$, Thorsdottir I, et al. Public health nutrition workforce development in seven European countries: constraining and enabling factors. Public Health Nutr. 2012;15(11):1989-1998. CrossRef. Medline

34. Walt G, Gilson L. Reforming the health sector in developing countries: the central role of policy analysis. Health Policy Plan. 1994;9(4):353-370. CrossRef. Medline

35. Berg A. Sliding toward nutrition malpractice: time to reconsider and redeploy. Annu Rev Nutr. 1993;13(1):1-16. CrossRef. Medline

36. Pelto GH, Freake HC; ASNS Long Range Planning Committee. Social research in an integrated science of nutrition: future directions. J Nutr. 2003;133(4):1231-1234. Medline

37. New York Academy of Sciences [Internet]. New York: The Academy; c2014 [cited 2014 Feb 18]. The Sackler Institute for Nutrition Science; [about 1 screen]. Available from: http://www. nyas.org/WhatWeDo/Nutrition/Agenda.aspx

38. Shekar M. Delivery sciences in nutrition. Lancet. 2008;371 (9626):1751-1751. CrossRef. Medline

39. Leroy JL, Menon P. From efficacy to public health impact: a call for research on program delivery and utilization in nutrition. J Nutr. 2008;138(3):628-629. Medline

40. Garrett JL. Improving results for nutrition: a commentary on an agenda and the need for implementation research. J Nutr. 2008;138(3):646-650. Medline

41. International Society for Implementation Science in Nutrition (ISSN) [Internet]. New York: ISISN; [cited 2015 Apr 15] . Available from: http://www. implementationsciencesociety.org/

42. Allen L, Gillespie S. What works? A review of the efficacy and effectiveness of nutrition interventions. Geneva: United Nations Administrative Committee on Coordination Sub-Committee on Nutrition; 2001. Co-published by the Asian Development Bank. Available from: http://www.adb.org/sites/default/files/ publication/27916/what-works-nutrition-interventions.pdf

43. Berg A. Sliding toward nutrition malpractice: time to reconsider and redeploy. Am J Clin Nutr. 1993;57(1):3-7. Medline 
44. Bennett S, Agyepong IA, Sheikh K, Hanson K, Ssengooba F, Gilson L. Building the field of health policy and systems research: an agenda for action. PLoS Med. $2011 ; 8(8)$ :e1001081.

CrossRef. Medline
45. National Research Council. Using science as evidence in public policy. Washington (DC): The National Academies Press; 2012. Available from: http://www.nap.edu/openbook.php? record_id $=13460$

\section{Peer Reviewed}

Received: 2015 Jan 11; Accepted: 2015 Mar 21; First Published Online: 2015 May 27

Cite this article as: Pham J, Pelletier D. Action-oriented population nutrition research: high demand but limited supply. Glob Health Sci Pract. 2015;3(2):287-299. http://dx.doi.org/10.9745/GHSP-D-15-00009.

(c) Pham et al. This is an open-access article distributed under the terms of the Creative Commons Attribution License, which permits unrestricted use, distribution, and reproduction in any medium, provided the original author and source are properly cited. To view a copy of the license, visit http://creativecommons.org/licenses/by/3.0/. When linking to this article, please use the following permanent link: http://dx.doi.org/ 10.9745/GHSP-D-15-00009. 